\title{
THE RADIOLOGICAL "DOUBLE CONTOUR" EFFECT IN THE LONG BONES OF NEWLY BORN INFANTS
}

\author{
BY
}

\author{
N. M. HANCOX, J. D. HAY, W. S. HOLDEN, P. D. MOSS, and A. S. WHITEHEAD \\ From the Mill Road Maternity Hospital, Liverpool, and the Department of Physiology and \\ Histology, University of Liverpool
}

(Received for Publication February 5, 1951)

The radiological appearance of a double contour on the sides of the long bones of infants has been noted by several writers since Chiari first drew attention to it in 1938. Many theories of its causation and significance have been advanced, including the view that it may be due to organic disease such as rickets or syphilis. Glaser, however, in 1949 suggested that this appearance may be seen in radiographs of normal, healthy bone, and that its production depends on the angle of projection. The results of the investigation described below support his view that a double contour effect may be seen in normal bones, but suggest that its origin is in the histological structure of the bone itself rather than in the technique of radiography.

\section{Investigation}

One hundred and seventeen infants, of whom the majority were premature, born in the Mill Road Maternity Hospital, Liverpool, have been studied, 97 during life and 20 after death. Of the living infants, 73 were regarded as healthy, 62 being premature, with birth weights of $5 \mathrm{lb} .8 \mathrm{oz}$. or less, and 11 mature. Twenty-four were abnormal on account of congenital defects or acquired disease.

Each infant was examined physically while in hospital and subsequently after discharge. All were radiographed before discharge from hospital, the mature infants usually during the second week, and the premature infants when the weight reached $5 \mathrm{lb}$. in the breast fed, and $5 \frac{1}{2} \mathrm{lb}$. in those artificially fed. The radiographic examination included anteroposterior and lateral projection of the limbs, with oblique and tangential views when required. A rotating anode tube with a $1 \mathrm{~mm}$. focal spot and non-screened films were used. The focal-film distance was usually 40 in. with KV 55, and Mas. 20.

\section{Results}

A double contour effect was noted on the radiographs of the long bones as a single, continuous, linear shadow running adjacent to the diaphysis on its outer side, and separated from it by a radiotranslucent strip about $1 \mathrm{~mm}$. in width (Figs. 1, 2, 3 , 4). This thin, pencilled line, which was never laminated, was limited to the diaphyseal portion of the bone, and never extended beyond the metaphyseal region, at which point it merged with the outline of the diaphysis. It was somewhat variable in its extent and position, being visible on both sides of some bones and on only one side of others. In some it extended the whole length of the diaphysis while in others it was limited to a part of the shaft. Commonly, though by no means invariably, it was present in both limbs. In some cases it was very obvious, in others it had to be looked for carefully. Variation in the focal-film distance or in the angle of projection of the radiographs produced no difference in the appearance of the double contour.

Healthy Infants. The 73 healthy infants showed no physical signs of organic disease while under observation. Blood alkaline phosphatase estimations in three revealed values within the normal range for infants $(25,22$, and 27 King Armstrong units), and in one the serum calcium level was $12.5 \mathrm{mg}$. and the phosphorus level $5.1 \mathrm{mg}$. per $100 \mathrm{ml}$. The mothers of all these infants were also regarded as healthy, and had negative blood Wassermann reactions and/or Kahn tests.

The double contour effect was noted in one or more bones in $20(27 \%)$ of the 73 cases examined. Of these $14(70 \%)$ showed the appearance in more than one bone. The bones most commonly affected were the tibia and ulna, followed by the fibula, radius, femur, and humerus. No double contours 
were seen in the ribs, clavicles, metatarsals, metacarpals, or phalanges.

The incidence of the double contour effect in individual bones is shown in Table 1 .

TABLE 1

InCIDENCE OF THE DOUble Contour EFfect IN INDIVIDUAL BONES

\begin{tabular}{ll|l|c}
\hline \multicolumn{1}{c|}{ Bone } & & $\begin{array}{c}\text { Number of Infants } \\
\text { Showing Double Contour }\end{array}$ & Percentage \\
\hline Tibia & $\cdots$ & 15 & 22 \\
\hline Ulna & $\cdots$ & 14 & 20 \\
\hline Fibula & $\cdots$ & 9 & 12 \\
\hline Femur & $\cdots$ & 7 & 10 \\
\hline Radius & $\cdots$ & 7 & 10 \\
\hline Humerus & $\ldots$ & 2 & 3 \\
\hline
\end{tabular}

The incidence of the double contour effect in combinations of bones in the same patient is shown in Table 2.

TABLE 2

INCIDENCE OF DOUBLe Contour EFFect IN Combinations of Bones in the Same Patients

\begin{tabular}{c|c|c}
\hline $\begin{array}{c}\text { Combination } \\
\text { of Bones }\end{array}$ & $\begin{array}{c}\text { Number of Infants } \\
\text { Showing Double Contour }\end{array}$ & $\begin{array}{c}\cdots \\
\text { Percentage }\end{array}$ \\
\cline { 2 - 3 } $\begin{array}{c}\text { Radius and } \\
\text { Ulna .. }\end{array}$ & 8 & 11 \\
\hline $\begin{array}{c}\text { Tibia and } \\
\text { Fibula .. }\end{array}$ & 6 & 8 \\
\hline $\begin{array}{c}\text { Tibia, Fibula } \\
\text { Radius, and } \\
\text { Ulna .. }\end{array}$ & 2 & 3 \\
\hline
\end{tabular}

The incidence of double contour effect in infants of varying maturity at birth is shown in Table 3 where the infants are divided into groups according to their birth weights. The high incidence of the effect in the infants of lowest birth weight is striking.

Amongst the healthy infants were four pairs of twins, two uniovular and two binovular. In one of the uniovular pairs both infants showed double contour effect, in the other it was well marked in one infant, but absent in the other. Of the binovular twins the effect was noted in both infants of one pair and in neither infant of the other pair.

Radiographs taken at intervals revealed that the length of time the double contour effect persisted varied from infant to infant, remaining in some for
TABLE 3

Incidence of Double Contour Effect at Different BirTh WeIGHTS

\begin{tabular}{|c|c|c|}
\hline Birth Weight & $\begin{array}{l}\text { Number of Infants } \\
\text { Showing Double } \\
\text { Contour }\end{array}$ & $\begin{array}{c}\text { Per- } \\
\text { centage }\end{array}$ \\
\hline Under 3 lb. .. & 5 & 80 \\
\hline 3 lb. -3 lb. 15 oz. $\ldots$ & 26 & 42 \\
\hline 4 lb. -4 lb. 15 oz. $\ldots$ & 27 & 26 \\
\hline 5 lb.-5 lb. 7 oz. & 5 & 20 \\
\hline 5 lb. 8 oz. -5 lb. 15 oz. & 3 & None \\
\hline $6 \mathrm{lb}$. and over & 7 & None \\
\hline
\end{tabular}

one month, in others for longer periods up to eight months after the initial radiograph. As a rule, the more pronounced the change initially, the longer it persisted. We did not note its reappearance in any case serially radiographed, though such an occurrence would be quite compatible with our histological studies. Nor did we see its later development as described by Glaser in infants whose initial films did not show the change.

Abnormal Infants. The double contour effect was noted in two $(8.4 \%)$ of the 24 abnormal infants included in the investigation.

Of these infants, six had congenital deformities, eight suffered from haemolytic disease, two showed radiological evidence suggestive of rickets, and five, with their mothers, had positive blood Wassermann and Kahn reactions. The double contour effect was seen in two of these five infants. It was not observed in the other 22 cases.

The congenital deformities were anencephaly, encephalocoele, lacunar skull, spina bifida, achondroplasia, and dyschondroplasia. The radiographs of the bones in these cases revealed the appearances characteristic of the deformities. The bones of the infants with haemolytic disease were of normal appearance. In the two infants with rickets, aged 6 months and 11 months, the metaphyseal changes typical of the condition were seen.

Of the five infants, all premature, whose blood Wassermann and Kahn reactions were positive, the two in whom the double contour effect was seen showed no radiological evidence of any other skeletal changes. The other three showed definite bone changes suggestive of syphilis in the form of osteochondritis, osteitis, and periostitis. These lesions tended to be multiple, affecting more than one bone, and to be asymmetrical in distribution.- 
FIG. 1.-Radiograph showing we 11 marked double contour e f f e c t more marked on the anterior surface of the tibia.

FIG. 2.-Enlargement of the same bone.

FIG. 1.
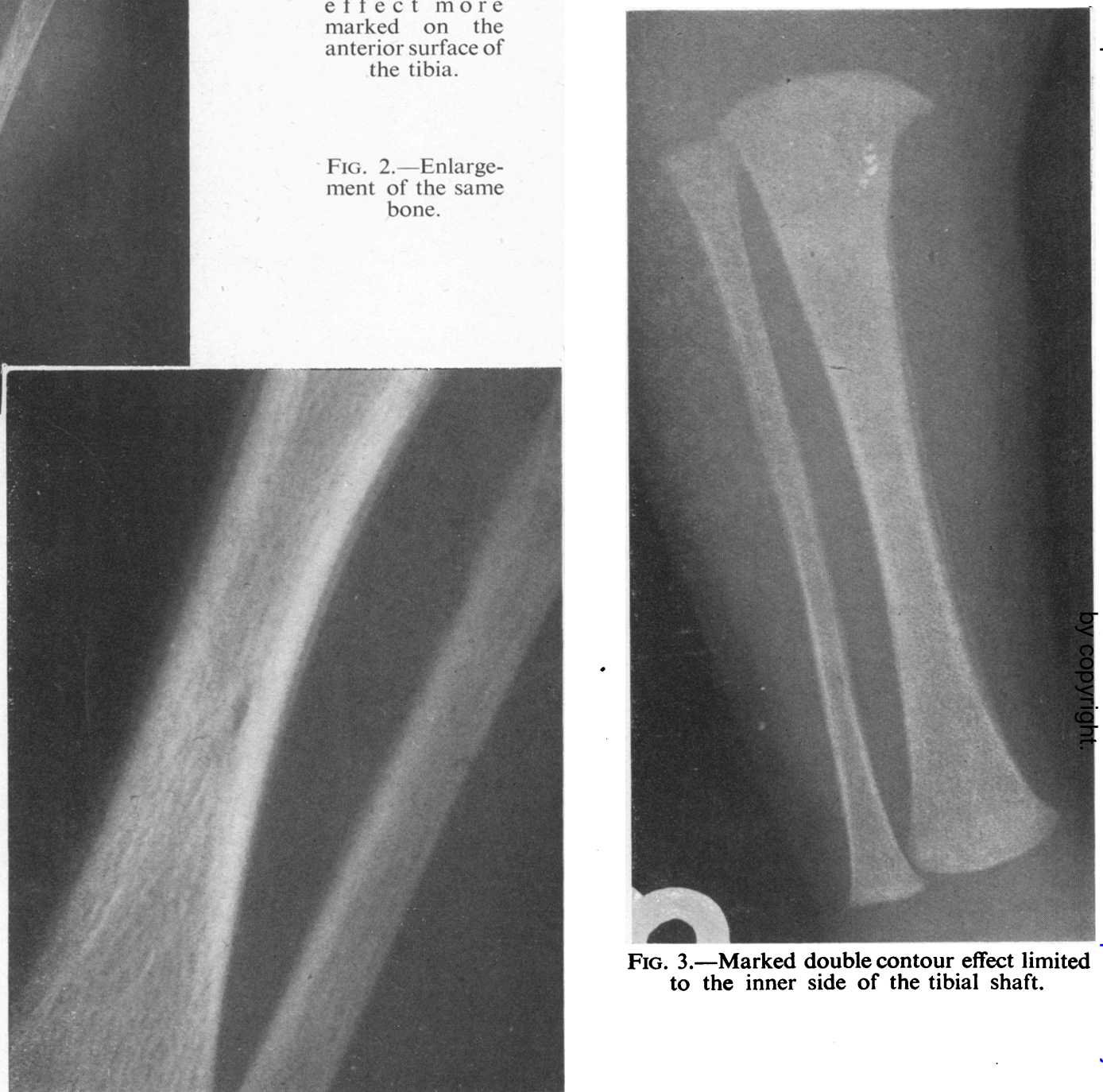

FIG. 3.-Marked double contour effect limited to the inner side of the tibial shaft.

FIG. 2.

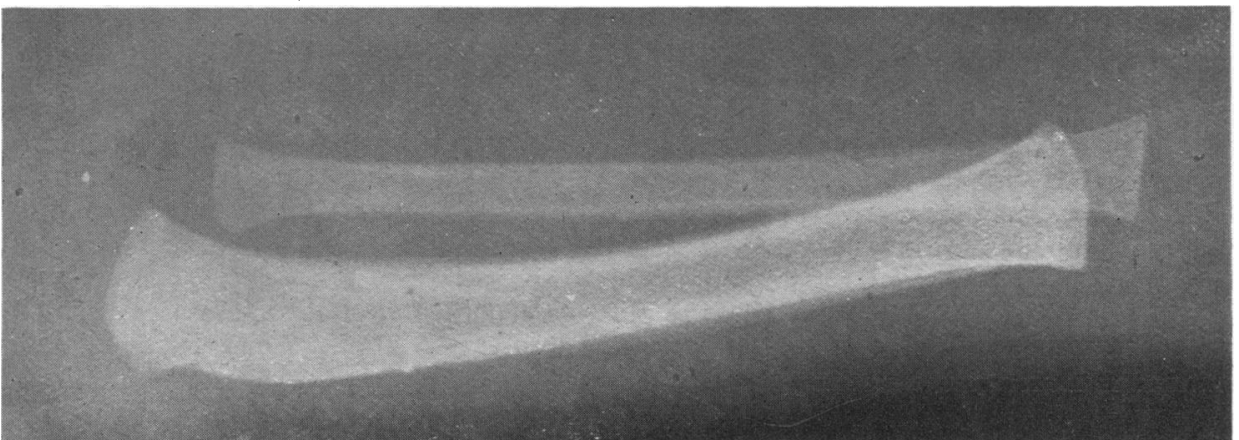

FIG. 4.-Double contour effect most marked at the lower end of the anterior tibial shaft and in the middle of the posterior surface. 


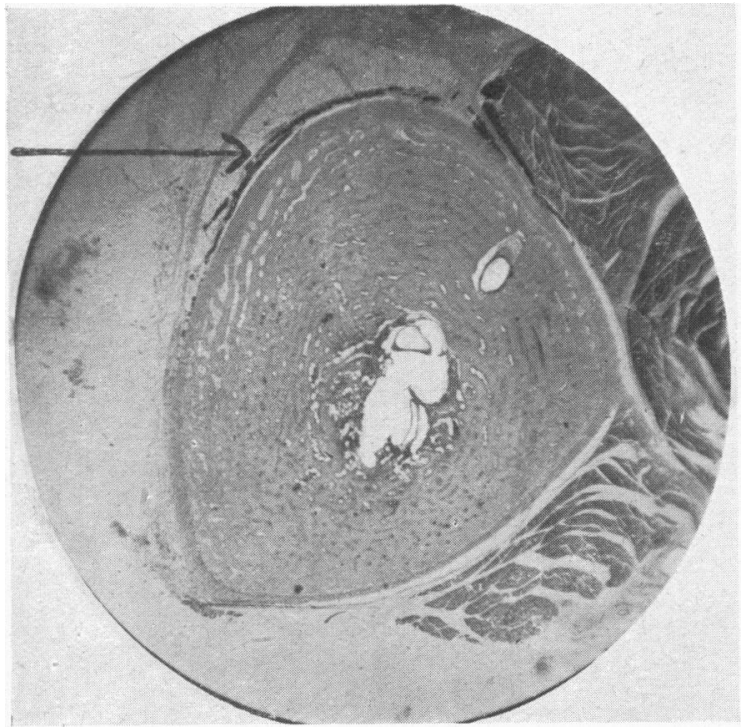

FIG. 5.-Cross section of tibia of Case 72 (low power photomicrograph). The arrow points to the Indian ink which had been injected in the region of the double contour. Note the porosity of the subadjacent bone tissue resulting from the large, arciform, primitive vascular channels.

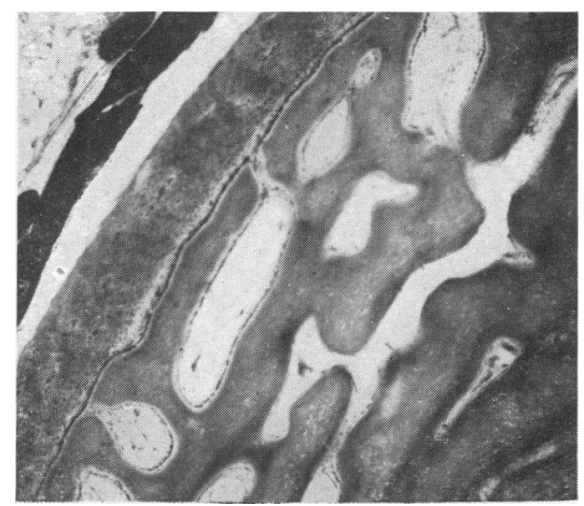

Fig. 7.-Higher power view of tibia of Case 72. The outermost portion of the bone is shown. The tissue is normal and its appearance suggests rapid deposition.
FIG. 6.-Cross section of control 음 bone. The vascular channels are $\rightarrow$ smaller and more uniformly dispersed, indicating a less concentrated $\mathbb{D}$ apposition of bone tissue.

\section{Histological Material}

In order to determine the histological appearances of the bones showing the double contour effect, post-mortem material was obtained from 20 other infants who had no known skeletal abnormality. The bones were removed and radiographed from different angles to demonstrate the double contour effect if any were present. It was observed in only two cases, and in these it was not well marked. The area of the bone showing the double contour effect was ' marked' for the histologist by inserting pins under radiographic control through the soft tissues of the limb down to the bone in the area, and then injecting Indian ink into the soft tissues round the bone at the points of the pins. The pins marked the area in the radiograph and the Indian ink identified that area to the histologist.

\section{Histology}

In the first case examined histologically the tibia and fibula were left in their natural relationship with some adherent soft tissue. After fixation and decalcification a block of tissue was excised by transverse cuts in the mid-shaft region and was embedded in paraffin wax. In the second, in which the Indian ink had been injected into the soft tissue around the bone where the double contour effect had been demonstrated radiologically, a similar block of tissue was embedded in low viscosity nitrocellulose. Control blocks were also prepared from bones which did not show the double contour effect.

The histological picture was essentially similar in both the affected cases. The bones appeared perfectly normal, except that in the region where 


\section{“DOUBLE CONTOUR” IN LONG BONES OF NEWBORNS}

the double contour had been demonstrated the bone tissue was notably reticular in appearance, trabeculae of woven bone surrounding very large primitive vascular canals which were often arciform (Fig. 5). The appearance almost suggested that there might be two outer boundaries to the shaft of the bone. In one case the outermost bone was continued toward the periosteum in the form of flame-shaped tongues.

The bone tissue in the regions described appeared normal histologically, and with the technique applicable to decalcified material, there was nothing to suggest the existence of 'osteoid borders' such as would be found in rickets. Moreover, the pattern formed by the trabeculae resembled that normally encountered where bone deposition is proceeding rapidly, such as in fracture callus or during the initial stages of membrane bone formation. The tall, basophil osteoblasts surrounding the bone also suggested intense bone deposition (Fig. 7).

It would appear that in the region of the double contour effect the bone tissue is more porous than usual, and that quite large and probably more or less continuous spaces occur in its substance. Such large spaces were not seen in the control sections (Fig. 6); they would obviously absorb less radiation than the surrounding denser bone, thereby probably accounting for the thin, radiolucent line on the inner aspect of the double contour described above. The outer portion of the contour, comprising the continuous linear shadow, is in all probability cast by the outermost trabeculae consisting of the most recently deposited bone tissue. It should, however, be stressed that only tentative conclusions are justified in view of the paucity of histological material.

The rather striking configuration of the bone tissue is probably a reflection of a localized acceleration of growth. Subperiosteal accretional deposition of bone tissue cannot proceed equally and uniformly around the entire perimeter of $\mathbf{a}$ developing bone since the ultimate sectional outline is never perfectly circular and is usually pyriform or even triangular. Increase in thickness of the shaft must then be attained by a differential deposition rate. The site of maximum deposition may vary from time to time which would account for the disappearance and reappearance of the double contour effect should this be observed.

\section{Discussion}

Incidence. While this investigation was in progress Glaser's paper (1949) was published. It seems clear that the double contour effect which he describes is similar to that which we have studied.
He investigated 100 premature infants at monthly intervals, and found the double contour effect in the ulna in 32 cases, in the radius in 27, in the tibia in 24 , and in the fibula in eight. The incidence in the various bones differs from that in our series, but is more likely to be an accurate indication of the true incidence in premature infants, since it is based on much larger numbers. He noted that the effect often appeared first in one bone and later in others; that its first appearance was commonly in the third and fourth months of life, and that it tended to disappear in the seventh, or, more frequently, the eighth month. In 67 mature infants whom he investigated by a single film of each bone taken on one occasion only, he found the double contour effect in the ulna in 46 , the radius in 37 , the tibia in 24 , and the fibula in 14 , and he noted that the changes tended to disappear about two months earlier than in the premature infants.

Causation. He states that the double contour effect is produced by the x-rays falling on a bone in a certain direction relative to the bone, its crests and the film, and supports his contention by films taken of the same bone in different positions relative to the direction of the rays. We were unable, in repeated experiments both with living infants and with excised bones, to relate the double contour effect to the projection of a crest or anatomical ridge; also many of our cases showed double contour whatever the position of the bone relative to the rays. Moreover, the histological appearance in the region of the double contour is not that of a crest, but of a localized exaggeration of appositional growth process in the bone. We believe, therefore, that the effect is not produced by projection but by this local acceleration of the growth of the bone.

Davidson and Merritt (1934) noted a periosteal reaction early in rickets. Von Chiari (1938) considered rickets to be a contributory, but not the main, factor in the causation of the double contour effect. He found pyodermia to be the most frequently associated condition, but did not regard it as of prime importance. He also rejected syphilis as a cause. Malmberg (1945) also regarded the effect as an early sign of rickets, because he found a double contour in $39 \%$ of 114 premature infants who had received prophylactic vitamin $D$, and in $64 \%$ of 42 controls who did not receive the vitamin, and also because he observed that many infants who showed the double contour effect later developed rickets. Infants of birth weights under $1,500 \mathrm{~g}$. showed the change twice as commonly as those over that weight. Glaser did not observe rickets develop in his infants showing the double contour effect. Similarly, it did not follow in our series. Moreover, such ancillary tests as were carried out in our cases 
failed to show any evidence of rickets, though it must be admitted that the infants could conceivably have suffered a transient relative deficiency of vitamin $\mathrm{D}$. In our opinion, therefore, the double contour effect is not caused by rickets.

Congenital syphilis is unlikely to be a cause of the double contour effect in view of the number of infants in whom the change was seen and who showed no other evidence of such infection. On the other hand, it may be impossible to differentiate radiologically between syphilitic periostitis and the double contour effect when the periostitis is not accompanied, as it usually is, by osteochondritis and osteitis. In such cases a diagnosis of syphilis should be based solely on other evidence.

A periosteal reaction in the shafts of the long bones has been described in infants suffering from hypervitaminosis A (Toomey and Morissette, 1947; Rothman and Leon, 1948). This reaction may have an irregular and fuzzy outline, or may take the form of a clearly defined periosteal line similar to the double contour effect. These bony changes have, however, been accompanied by other manifestations of hypervitaminosis such as loss of weight, progressive emaciation, haemorrhagic rhinitis, and loss of hair, and have been produced by the prolonged administration of vitamin $A$ in doses of 100,000250,000 units daily. The infants in this series were daily receiving 10,000 units of vitamin $\mathrm{A}$, and none showed such a syndrome. It is, therefore, considered very unlikely that hypervitaminosis A plays any part in the production of the double contour effect in these infants. It must be remembered, however, that it is common practice to give what is considered to be an adequate daily amount of vitamin $D$ in a form that includes vitamin $A$ in quantities which may possibly be excessive for some infants. Overdosage of vitamin A must, therefore, be considered as a possible cause of a double contour effect in an infant in whom the intake of the vitamin is unknown.

Ascorbic acid was administered to these infants in adequate doses from the second week of life, and the radiological appearances of scurvy are quite unlike the double contour effect.

Infantile cortical hyperostosis is characterized radiologically by gross changes in the long bones which do not resemble the double contour effect. Moreover, the mandible and clavicles are the bones most often affected, and there are accompanying fever and constitutional disturbances.

Infants with long bones fractured during delivery have not been included in this series, but the radiological appearances in the region of fractures in other infants bore no resemblance to the double contour effect. Also there was no significant difference between the degree and location of the double contour effect in infants in this series born by breech delivery, and in those born by vertex presentation. Similarly, there is no evidence to support the view that the appearance is due to subperiosteal haematoma. In fact, the histological findings completely refute such a theory. Trauma, then, cannot be regarded as in any way responsible for the double contour effect. Similarly, there is no evidence that osteogenesis imperfecta plays any part in its production.

The double contour effect is a normal radiological finding in the long bones of some newly born infants. The cause is shown histologically to be due to a local exaggeration of the normal appositional growth of bone. The effect is visualized best and most frequently in the younger infants, particularly the premature ones. Its appearance is not related to any known type of disease, and its presence in association with other diseases must be regarded as being entirely fortuitous.

\section{Summary}

An investigation into the occurrence and cause of a double contour effect in radiographs of the long bones of infants is described. Theories of causation are discussed and evidence is submitted in favour of its being due to local exaggeration of the normal growth process.

We wish to express our thanks to Professor N. B. Capon for his helpful advice in the presentation of our findings, and to the staff of the Mill Road Maternity Hospital for their willing cooperation during the investigation.

\section{REFERENCES}

Chiari, O. von (1938). Arch. Kinderheilk., 115, 66, 149. Davidson, L. T., and Merritt, K. K. (1934). Amer. J. Dis. Child., 48, 281.

Glaser, K. (1949). Amer. J. Roentgenol., 61, 482.

Malmberg, N. (1945). Acta paediatr., Stockh., 32, 626.

Rothman, P. E., and Leon, E. E. (1948). Radiology, 51, 368.

Toomey, J. A., and Morissette, A. (1947). Amer. J. Dis. Child., 73, 473. 